\title{
Correction Trophological Violations at Enteric Fistula
}

\author{
K. Shakeyev, M. Zhanasova, G. Stepanenko*, G. Tastanova, E. Darmenov, M. Muratbekov \\ Department of Surgical Diseases №1, General Medical Faculty, Karaganda State Medical University, Kazakhstan
}

Copyright $\odot 2016$ by authors, all rights reserved. Authors agree that this article remains permanently open access under the terms of the Creative Commons Attribution License 4.0 International License

\begin{abstract}
Correction of malnutrition with enteric fistula is a problem that is caused by difficulties in the normalization of fluid and electrolyte balance and protein balance. Effective way of correcting violations trophological is transfistula enteral nutrition that helps to stabilize the condition of patients, respectively, and reduce the number of poor results in 1.8 times.
\end{abstract}

Keywords Intestinal Fistulas, Fluid and Electrolyte Disorders, Enteral Nutrition, Nutritional Status, Complications

\section{Introduction}

The relevance of changes in homeostasis in enteric fistulas are one of the complex problems of modern clinical medicine, due to continued growth in the number of diseases of the intestinal tract, which produce intestinal fistulas $[1,2,3]$.

Marked increase in the incidence of diseases in which intestinal fistula formation and thus themselves fistula complications [4]. Particular difficulties arise in the treatment of immature intestinal fistulas, where mortality is high enough and is $82-90 \%[5,6]$.

Unformed intestinal fistulas are often accompanied by the formation of purulent cavities and streaks with the development of intoxication and exhaustion. The nature of the complications affect the level of intestinal fistula: the proximal location of the fistula, the greater the loss of electrolytes, proteins and enzymes, and the more pronounced irritant effect of the intestinal secretions of the surrounding tissue. At high fistulas, due to losses through the wound, developing water-electrolyte and protein disorders, and the mortality rate reaches $67-71 \%$ [7].

Patients with immature fistulas on the background of purulent wound infection progresses depletion of varying severity, which is due to large losses of intestinal juice and long-term toxicity. The mechanism of auto-intoxication begins with reducing the osmolarity of the extracellular fluid and an increase in extracellular fluid volume, which leads to cell hydration and decrease enzyme activity and impaired metabolism [8].

\subsection{Study Objective}

Study the effectiveness of the correction nutritional status at immature enteric fistulas.

\section{Materials and Methods}

The object of the study were 57 patients with high-enteric fistula, who were treated from 2008 to 2013 in proctology department of the regional hospital in Karaganda.

We have developed a method of introducing feed solutions using irrigation apparatus (Irrimatic), which consists of a base which includes a vessel for the liquid and a pump mounted tube with conical tip which provides a seal with the introduction of nutrient solutions at a certain pressure and speed. Adjust the intensity of the introduction of the solution is carried out mechanically by means of a lever.

To compare the efficiency of the developed method for the treatment of 57 patients with unformed intestinal fistulas were divided into 2 groups. Distribution of patients according to the type of fistula (Table 1).

Table 1. Distribution of patients according to the type of intestinal fistula in the two groups

\begin{tabular}{|c|c|c|c|c|}
\hline \multirow{2}{*}{ Type of fistula } & \multicolumn{2}{|c|}{ main group, $\mathrm{n}=28$} & \multicolumn{2}{c|}{ control group, $\mathrm{n}=29$} \\
\cline { 2 - 5 } & abs. & $\%$ & abs. & $\%$ \\
\hline The first type & 8 & 28,5 & 7 & 24,2 \\
\hline Second Type & 7 & 25 & 7 & 24,2 \\
\hline The third type & 6 & 21,5 & 6 & 20,6 \\
\hline The fourth type & 7 & 25 & 9 & 31 \\
\hline TOTAL & 28 & 100 & 24 & 100 \\
\hline
\end{tabular}

The main group $(n=28)$ of patients, which were used in the clinic developed treatments and a control group $(n=29)$, where traditional methods of treatment.

In the study group in order to protect the skin around the wound with a massive outpouring of intestinal juices held aspiration. Criteria for evaluation of nutritional status are weight and height of the patient, is used for the calculation of 
Lorentz formula: $=$ PMT $(\mathrm{Pc}-100)-[(\mathrm{Pc}-150) \mathrm{K}]$, where RMT - recommended body weight $(\mathrm{kg})$; Pc - height $(\mathrm{cm})$; K coefficient of 0.2 for men and 0.4 for women. However, if you cannot measure the amount of growth is determined by the shoulder. In our study, mild malnutrition was not observed. Table 2 shows the calculations and laboratory data and anthropometric studies on the basis of which the patients were divided into groups, according to data on the degree of violation of nutritional status.

Table 2. Evaluation of nutritional status by the method of Luft VM

\begin{tabular}{|c|c|c|c|c|}
\hline \multirow{3}{*}{ Performance } & \multicolumn{4}{|c|}{ Indicators of malnutrition } \\
\hline & \multicolumn{2}{|c|}{ Middle } & \multicolumn{2}{|c|}{ Heavy } \\
\hline & Main group & $\begin{array}{c}\text { Control } \\
\text { group }\end{array}$ & $\begin{array}{l}\text { Main } \\
\text { group }\end{array}$ & $\begin{array}{c}\text { Control } \\
\text { group }\end{array}$ \\
\hline $\begin{array}{l}\text { MT*, \% } \\
\text { RMT** }^{*}\end{array}$ & $71-79$ & $71-80$ & $57-68$ & $58-68$ \\
\hline BMI, $\mathrm{kg} / \mathrm{m}^{2}$ & $15-16$ & $12-14$ & $16-17$ & $13-17$ \\
\hline $\mathrm{OP}, \mathrm{cm}$ & $>24-25 \mathrm{~cm}$ & $20-23$ & $<20$ & $<20$ \\
\hline Lymphocytes & $900-1500$ & $950-1500$ & $<900$ & $<900$ \\
\hline Albumin $\mathrm{g} / \mathrm{L}$ & $25-30$ & $25-30$ & $<25$ & $<25$ \\
\hline
\end{tabular}

Note - MT*- weight, PMT $^{* *}$ - recommended weight

From this table, it is obvious that in severe malnutrition changes in laboratory parameters such as lymphocytes and albumin reflect the degree of malnutrition. Anthropometric data as measurement arm circumference, more accurately reflect the severity of depletion of patients. Volume shoulder in severe less than $20 \mathrm{~cm}$, and is directly proportional to BMI reduced to $14-15 \mathrm{~kg} / \mathrm{m}^{2}$.

The degree of malnutrition in patients with high enteric fistula was assessed by laboratory parameters such as lymphocytes and albumin, and noted that these figures are subject to change in the dynamics of intense than anthropometric measures. For the correction of fluid and electrolyte disorders, in addition to infusion therapy appropriate use of enteral nutrition in immature transfistula high enteric fistulas.

The method of enteral nutrition transfistula was applied in 28 patients with enteric fistulas. Indication for the proposed method is an expression of the power failure, and technical capacity to carry out enteral nutrition.

Assessment of the nutritional status of patients was performed according to the criteria VM Luft and IE Horoshilova. Patients had malnutrition of moderate and severe.

To evaluate the effectiveness of the developed method of enteral nutrition patients were divided into 2 groups. In the main group -28 patients ( 20 with medium and 8 with severe malnutrition), along with the usual treatment was performed enteral nutrition developed technique. In the control group 29 patients ( 25 with moderate and 4 with severe malnutrition) traditional regimen including parenteral nutrition. Management of patients with enteric fistulas included soft products, adequate fluid resuscitation with correction fluid and electrolyte disorders, local treatment of wounds. With abundant outpouring of intestinal juices in the open festering wound in these patients used the protection of the skin around the wound and recurrent aspiration of intestinal secretions using electric pumps in the control group. In infusion therapy comprises an amino acid mixture (infezol, Aminoplasmal), albumin, fresh frozen plasma.

In the control group applied a traditional management of intestinal secretions in diverting knee intestine. However, a large part of the solution poured into the wound because no system for leaks, since the diameter of the catheter does not always coincide with the size of the intestinal fistula. In the study group (28 patients) in the developed technique was introduced nutrient solutions in the outlet segment with the apparatus. The average rate of introduction of feed solutions was $10 \mathrm{~mm} / \mathrm{min}$ on a scale unit. If you exceed the speed of $15-20 \mathrm{~mm} / \mathrm{min}$, respectively, increased intraluminal pressure, leaks and broken solution follows a retrograde, pouring into the wound. Depending on the condition of the intestinal loops rate of administration can vary. The basis of the nutrient solutions are broth where further added enzymes (festal, Creon), glucose and vitamins. With this method, introduced into the lumen of the small intestine nutrient solutions provide to $1000-1500 \mathrm{kcal} /$ day. at the actual energy consumption in these patients an average of $2200-2400 \mathrm{kcal} /$ day. Introduction of the complex of amino acids is more effective than the use of the finished protein preparations. This principle has been used in the correction of disturbances protein. As the protein balance correction using amino acid solutions (infezol, Aminoplasmal) and fresh frozen plasma (FFP).

\section{Study Results}

When immature enteric fistulas in the process of adopting this method of enteral nutrition transfistula managed to get the normalization of nutritional status in 26 patients of the main group; including reduction in the degree of malnutrition and dehydration obtained in 23 patients (increased plasma concentrations of albumin, the normalization of the number of lymphocytes), and at 3 achieved stabilization of persistent nutritional status, which allowed surgery. In the control group, positive results were obtained in 21 as a stabilization of malnutrition without reducing its power, 8 patients had an unsatisfactory result.

The applied method of enteral nutrition in immature enteric fistula allows obturation fistula conical tip, warning retrograde nutrient solutions and enabling them to adjust the speed and pressure of injected solution. When immature intestinal fistulas, which opened in poorly delineated cavity and / or in the free abdominal cavity to hold enteral nutrition is not always possible, and the local treatment of wounds is still a difficult task. 
Table 3. Results correction homeostasis during the treatment

\begin{tabular}{|c|c|c|c|c|}
\hline \multirow{2}{*}{ Performance } & \multicolumn{2}{|c|}{ Main group, $\mathrm{n}=28$} & \multicolumn{2}{|c|}{ Control group, $n=29$} \\
\hline & before treatment & after treatment & before treatment & after treatment \\
\hline Total protein, g/ 1 & $38 \pm 0,85$ & $59 \pm 0,79 *$ & $43 \pm 0,68$ & $50 \pm 0,67$ \\
\hline $\mathrm{K}, \mathrm{mmol} / \mathrm{l}$ & $2,5 \pm 0,35$ & $3,3 \pm 0,35$ & $2,0 \pm 0,44$ & $3,1 \pm 0,44$ \\
\hline $\mathrm{Na}, \mathrm{mmol} / \mathrm{l}$ & $100 \pm 0,45$ & $128 \pm 0,45 *$ & $102 \pm 0,45$ & $118 \pm 0,45^{*}$ \\
\hline $\mathrm{Ca}, \mathrm{mmol} / \mathrm{l}$ & $1,8 \pm 0,65$ & $1,9 \pm 0,65$ & $1,7 \pm 0,12$ & $1,9 \pm 0,12 *$ \\
\hline $\mathrm{Hb}, \mathrm{g} / \mathrm{L}$ & $68 \pm 0,69$ & $88 \pm 0,69 *$ & $72 \pm 0,28$ & $78 \pm 0,22$ \\
\hline Erythrocytes h10 $12 / 1$ & $2,2 \pm 0,34$ & $3,2 \pm 0,37$ & $2,0 \pm 0,84$ & $2,9 \pm 0,81 *$ \\
\hline Leukocytes, 10h9 / 1 & $11 \pm 0,18$ & $8 \pm 0,14$ & $12 \pm 0,57$ & $10 \pm 0,53$ \\
\hline
\end{tabular}

In the analysis of these data marked the best results in the study group. As a result of applying a method of treating a basic group able to obtain good results in 15 patients $(57,1 \%)$, satisfactory results in $9(32.1 \%)$ and poor in $3(10.8 \%)$. In the control group, with the following results - in 6 patients $(17.2 \%)$, good, satisfactory in $10(34.4 \%)$ and poor in 14 (48.4\%). In our observations violation nutritional status assessed in 57 patients, correction of protein and water-electrolyte imbalance produced depending on the degree of violation. In order to evaluate the effectiveness of treatment, the patients were divided into two groups, the main group of patients -28 (20 medium and 8 with severe malnutrition). In the control group, 29 patients (25 with moderate 4 severe malnutrition), ready to use preparations of protein - casein and albumin. Assessment of nutritional status of patients was carried out according to the criteria VM Luft and I. E. Horoshilova $[9,10]$. Dynamics of changes in laboratory parameters in the groups are presented in Table 3.

Positive dynamics of such important indicators as the total protein in the study group by 1.5 times, and 1.1 times the control. The effectiveness of the use of amino acid complex in the correction of protein balance leads to positive changes in the main group.

\section{Conclusions}

1) The basis of the pathophysiological changes at high enteric fistulas are malnutrition, water and electrolyte disturbances. And the severity of these changes depends on the location of the fistula and the presence of purulent infection.

2) For the purpose of correction of malnutrition and nutritional status normalization expedient transfistulna enteral nutrition that helps to stabilize the condition of patients and thus to reduce the number of poor results in 1.8 times.

3) The basis of the principles of pathophysiology therapy hydropenias is restoration of water and salt homeostasis, rehydration therapy, rehabilitation of drinking mode, restoring the volume of circulating blood transfusion and water-salt mixtures.

4) The mechanism of auto-intoxication begins with reducing the osmolarity of the extracellular fluid and an increase in extracellular fluid volume, which leads to cell hydration and decrease in enzyme activity and impaired metabolism.

5) Complicated mechanisms of isoosmolar hydropenias, enteral exsiccosis, hypochloremia, the loss of intestinal juice irretrievably out hydrogencarbonate solution and a liquid that leads to the disruption of intracellular dehydration and acid-base balance. Consequently, the preservation of intestinal juice or decrease its loss allows you to save the acid-base balance.

6) Positive dynamics of such important indicators as the total protein in the study group by 1.5 times, and 1.1 times the control; $\mathrm{Hb}$ level in the study group grown up by 1,3 times and 1,08 times in the control group. The effectiveness of the use of amino acid complex in the correction of protein balance leads to positive changes in the main group.

7) Due to used methods of treatment patients with high-enteric fistula we have improved results of correction homeostasis during the treatment: prevented massive losses of electrolytes, protein and granted maximal income of feed solutions using irrigation apparatus.

\section{REFERENCES}

[1] An VK, VL Rivkin Emergency proctology. - M: Medpractics, $2003-144$ p.

[2] Kanshin NN, Volenko A. Rudin EP and others. Prevention of postoperative complications in surgery of the colon // International Surgical Congress. New technologies in surgery: Proceedings. - Rostov-on-Don, 2005 - S. 351.

[3] Sofronov DV, NI Bogomolov Surgical treatment of diseases and injuries of the colon // Journal of Surgery. - 2005. - №2. S. 21-24.

[4] Abdullaev M., Popov IV Diverticular disease of the colon // Journal of Surgery of Kazakhstan. - 2008. - №4. - P. 51-52. 
[5] Luft VM Nutritional support of patients in critical conditions as the base method for correction of metabolic disturbances // Herald intensive care. - 2002. - № 3. - S. 5-6.

[6] IE Khoroshilov Guidelines for Parenteral and Enteral Nutrition. - St. Petersburg: Normed-izdat. - 2000 - 376 pages.
[7] Woodmann G., et al. Are differences in stage at presentation a credible explanation for reported differences in the survival of patients with colorectal cancer // Br. J. Cancer. - 2001. - Vol. 85 (6). - P.787-790.

[8] Doherty GM, Lowney JK The Washington Manual of Surgery. - $2002-778$ p. 